\title{
Perilaku Makan Gajah Sumatera (Elephas Maximus Sumatranus) Di Taman Margasatwa Ragunan
}

\author{
Rena Riana Anita ${ }^{1}$, Dewi Elfidasari ${ }^{1}$, Donny Gunaryadi ${ }^{2}$ \\ ${ }^{1}$ Program Studi Biologi, Fakultas Sains dan Teknologi,Universitas Al Azhar Indonesia, Jl. Sisingamangaraja, \\ Kompleks Masjid Agung Al Azhar, Kebayoran Baru, Jakarta Selatan 12110 \\ ${ }^{2}$ Flora \& Fauna International - Indonesia Programme \\ Penulis untuk korespondensi/Email: renariana@gmail.com
}

\begin{abstract}
Abstrak - Gajah Sumatera (Elephas maximus sumatranus) merupakan subspesies dari gajah Asia yang hidup di Pulau Sumatera, Indonesia. Gajah merupakan spesies kunci sehingga harus dijaga kelestariannya. Oleh karena itu diperlukan adanya konservasi terhadap gajah. Taman Margasatwa Ragunan (TMR) merupakan salah satu kawasan konservasi eksitu. Pengamatan perilaku makan gajah di kawasan eksitu penting dilakukan untuk mengetahui mekanisme adaptasi gajah di kawasan eksitu yang bukan merupakan habitat aslinya karena sebagian besar aktivitas makan gajah dihabiskan untuk aktivitas makan. Pengamatan perilaku makan bertujuan untuk mendeskripsikan perilaku makan gajah sumatera di TMR. Penelitian dilakukan dengan pengamatan perilaku makan empat ekor gajah yang terdiri dari dua ekor gajah dewasa dan dua ekor gajah anakan yang meliputi: waktu aktivitas makan, jenis makanannya, perilaku makan, dan interaksi yang terjadi selama aktivitas makan. Metode pengamatan dilakukan dengan focal observastion. Analisis data yaitu menggunakan analasis deksriptif dan dengan membandingkan hasil presentase perilaku makan gajah yang terlihat. Hasil yang diperoleh adalah terdapat tiga perilaku gajah yaitu mengambil, memotong dan mengunyah makanan. Perbedaan perilaku gajah dipengaruhi oleh faktor umur dan jenis pakan gajah yang diberikan oleh perawat TMR.
\end{abstract}

Abstract - Sumatran Elephants (Elephas maximus sumatranus) is one of Asian elephants subspecies that live in Sumatra Island, Indonesia. Elephants are a key species that must be preserved. Therefore, it is necessary to do a conservation about elephants. Taman Margasatwa Ragunan (TMR) is one of the exsitu conservation area. An observation about elephant feeding behavior in ex-situ area is important to know the mechanism of elephant adaptation in the ex-situ area which is not their original habitat because most of elephant activity is spent on feeding activity. The purpose of this observation is to describe the feeding behavior of Sumatran elephant in TMR. This observation was conducted by observing the eating behavior of four elephants consisting of two adult elephants and two baby elephants which included: the time of feeding activity, the type of food, the eating behavior, and the interactions that occurred during feeding activity. Data analysis is using descriptive analysis and by comparing the percentage of elephant feeding behavior. The result obtained is there are three behaviors of elephants in TMR during feeding: taking, cutting, and chewing foods. Differences in elephant behavior are affected by age and type of foods.

Keywords - Elephants, Sumatran Elephants, Eating behaviour, Ragunan Wildlife Park

\section{PENDAHULUAN}

$\mathrm{G}^{3}$ ajah Sumatera (Elephas maximus sumatranus) merupakan subspesies dari gajah Asia (Elephas maximus). Gajah Sumatera hidup di Pulau Sumatera. Gajah Sumatera berbeda dengan gajah Asia lainnya. Pada gajah Sumatera terdapat 20 pasang tulang rusuk, sedangkan subspesies gajah Asia lainnya memiliki 19 pasang tulang rusuk [1]. Gajah merupakan salah satu spesies kunci di alam liar yang harus dijaga kelestariannya. Untuk itu diperlukan langkah-langkah konservasi sebagai upaya menjaga kelestariannya. Status gajah Sumatera saat ini adalah kritis terancam punah. Penyebab dari penurunan populasi gajah Sumatera ini adalah habitat alaminya yang semakin berkurang, pemburuan liar, dan konflik antara manusia-gajah [2]. 
Oleh karena itu diperlukan adanya konservasi terhadap gajah [3]. Konservasi dapat dilakukan secara ex-situ maupun in-situ. Salah satu penampungan gajah Sumatera sekaligus tempat konservasi yang terletak di DKI Jakarta adalah Taman Margasatwa Ragunan (TMR). Tempat ini berfungsi sebagai tempat perlindungan dan pemeliharaan satwa Indonesia termasuk gajah Sumatera.

Perilaku adalah hubungan antara organisme dan lingkungannya. Perilaku dapat dipengaruhi oleh beberapa faktor yaitu genetik dan lingkungan. Fungsi perilaku yaitu agar hewan tersebut dapat bertahan hidup dengan adaptasinya terhadap perubahan lingkungan [4].

Gajah dilahirkan dengan otak yang besarnya proposional dan kompleks yang dapat berkembang sejak lahir. Oleh karena itu gajah dapat berasosiasi sehingga memiliki kemampuan untuk memecahkan permasalahan. [5]. Beberapa perilaku harian gajah menurut [6], meliputi pergerakan, minum, mandi, istirahat, mengepakkan telinga, kawin, dan makan.

Sebanyak 50\% aktivitas gajah digunakan untuk makan. Gajah dapat mengkonsumsi lebih dari 400 spesies tumbuhan yang berbeda. Makanan gajah di alam berupa; kulit pohon, buah, daun, bunga dan batang. Konsumsi bunga dan buah pada gajah bergantung ketersediaan yang ada di habitatnya [7]. Belalai, gading, gigi, kaki dan indra penciuman merupakan alat bantu gajah untuk makan. Belalai gajah panjang dan lentur, sehingga dapat digunakan untuk mengambil benda kecil ketika gajah sedang mencari makanan. Gading biasanya digunakan untuk menemukan endapan garam didalam tanah dan kadang-kadang digunakan untuk mencari air. [8]

Gigi gajah yang besar membantu gajah untuk mengunyah makanan. Gigi tersebut cukup kuat untuk memecah kayu keras, dan masing-masing gigi memiliki fase pergantian gigi selama beberapa kali selama hidupnya. Kaki gajah yang besar tidak hanya berfungsi untuk berjalan tetapi juga berfungsi sebagai alat bantu saat gajah sedang melakukan aktivitas makan. Indra penciuman gajah juga sensitifitas yang bagus, yang memungkinkan gajah untuk menemukan makanan dan air dari jarak jauh.

Pengamatan terhadap perilaku makan gajah di kawasan eksitu penting sebagai salah satu data referensi cara gajah dapat bertahan hidup di tempat yang bukan merupakan habitat aslinya. Tujuan penelitian ini untuk memberi gambaran secara lebih detil terkait perilaku makan gajah Sumatera di TMR yang merupakan habitat eksitu

\section{METODE PENELITIAN}

Pengamatan ini dilakukan di kawasan kandang Gajah Sumatera dalam Taman Margasatwa Ragunan, Jakarta Selatan pada bulan Maret 2015 hingga September 2015. Pengamatan dilakukan setiap hari pada pukul 08:30-16:00 WIB. Objek pada pengamatan ini adalah 4 ekor gajah Sumatera yang memiliki umur yang berbeda. Dua gajah dewasa (Mulyani dan Agustin) dan dua gajah anakan (Pangeran dan Lestari). Peralatan yang digunakan yaitu peralatan tulis, stopwatch ALBA, dan handycam SONY

Metode yang dilakukan dalam pengamatan perilaku makan gajah Sumatera di TMR adalah pengamatan langsung terhadap objek dan pengambilan rekaman gambar. Pengambilan rekaman gambar dilakukan selama gajah melakukan aktivitas makan dengan memilih salah satu individu dan direkam setiap 5 menit (metode scan sampling) saat melakukan aktivitas makannya [9].

Analisis rekaman gambar dilakukan selama bulan April-Mei 2015. Rekaman aktivitas makan gajah yang telah disunting dianalisis dengan metode focal observation yaitu dengan cara mengamati aktivitas gajah yang terlihat di rekaman gambar berdasarkan data perilaku yang akan dikumpulkan. Data perilaku dikumpulkan pada saat aktivitas makan yaitu: waktu aktivitas makan dan jenis makanan, perilaku makan dan interaksi yang terjadi.

Pengambilan data untuk waktu aktivitas makan dilakukan dengan cara mencatat waktu saat gajah diberikan makan dan jenis-jenis makanan yang diberikan oleh perawat gajah di TMR. Perilaku makan yang dilakukan gajah dicatat pada saat aktivitas makan berdasarkan jenis makanan dan umur gajah untuk data perilaku gajah. Selain itu, hal yang dicatat adalah berbagai macam cara yang dilakukan gajah pada makanannya diamati saat aktivitas makan diamati. Data interaksi yang terjadi diambil dengan cara melihat interaksi yang terjadi sesama spesies gajah saat aktivitas makan.

Data kuantitatif adalah data presentase frekuensi perilaku makan setiap waktu makan gajah Sumatera dengan anak menggunakan rumus: 
$\%$ Perilaku $=\frac{\text { Frekuensi Perilaku }}{\text { Total Frekuensi Perilaku }} \times 100 \%$

Data kuantitatif diolah menggunakan program Microsoft Excel 2007. Hasil tabulasi data kuantitatif akan disajikan menggunakan diagram.

\section{HASIL DAN PEMBAHASAN}

\section{Aktivitas Harian dan Jenis Makanan Gajah Sumatera di TMR}

Aktivitas harian gajah Sumatera yang terdapat di TMR yaitu makan (41\%), istirahat (34\%), mandi atau berkubang (9\%), dan minum (2\%). Gajah berisitirahat pada pukul 12:00-14.00 WIB. Perilaku istirahat pada gajah di TMR yaitu terlihat pada saat gajah bersandar di tiang tidak melakukan aktivitas apapun.

Gajah biasanya berkubang pada pukul 10.00 dan pukul 14.00. Saat berkubang gajah mulai mendekati kolam kecil yang terdapat di kandang, lalu Ia mulai menyemprotkan air ke tubuhnya. Berkubang pada gajah dilakukan untuk menjaga suhu tubuhnya saat Ia sedang merasa kepanasan [10].

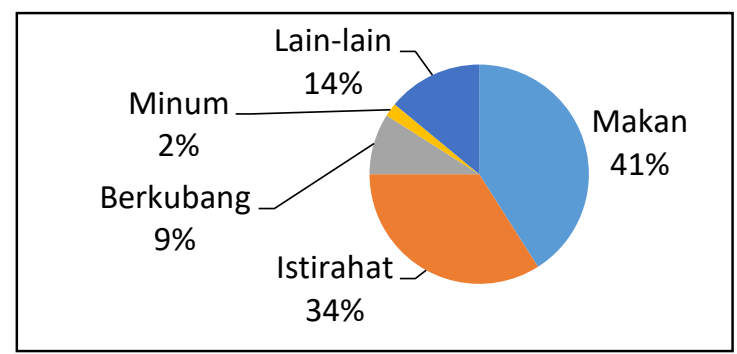

Gambar 1. Presentase frekuensi aktivitas harian Gajah sumatera di TMR

Jenis makanan yang diberikan kepada Gajah Sumatera di TMR yaitu rumput gajah, kelapa muda, pepaya, pisang, jagung, kacang panjang, dan ubi. Pada pagi hari rumput gajah diberikan sekitar pukul 08:30-09:40 WIB dan pada sore hari sekitar pukul 14:30-15-30 WIB. Rumput paling banyak diberikan pada sore hari sebelum perawat meninggalkan kandang setelah itu gajah dibiarkan melakukan aktivitas makan. Hal ini karena sore hari adalah waktu sebelum gajah memulai waktu aktifnya [11].

\section{Perilaku Makan Gajah Sumatera di TMR}

Rumput gajah yang diberikan ke gajah memiliki panjang sekitar satu meter. Gajah memotong rumput yang akan dimakannya dengan dua cara. Cara yang pertama yaitu menahan rumput dengan salah satu kaki depannya lalu bagian sisi lain dari rumput itu ditarik oleh belalai dengan cara melilitkan belalainya sehingga rumput terpotong. Cara yang kedua yaitu menahan rumput dengan giginya, lalu sisi lain rumput dililit oleh belalai dan ditarik. Biasanya perilaku memotong rumput ini dilakukan oleh Lestari dan Pangeran yang usianya masih satu tahun. Hal tersebut terlihat pada Gambar 2, gajah anakan menunjukkan presentase perilaku memotong dan mengunyah makanan yang lebih besar daripada gajah dewasa.

Menurut [6], gajah Asia memakan rumput dengan cara melilitkan belalainya lalu ditarik dan dimasukkan ke dalam mulut. Menahan rumput dengan satu kaki depan dan menarik makanannya dengan belalainya merupakan cara untuk memperkecil bagian makanan yang akan dimakan.

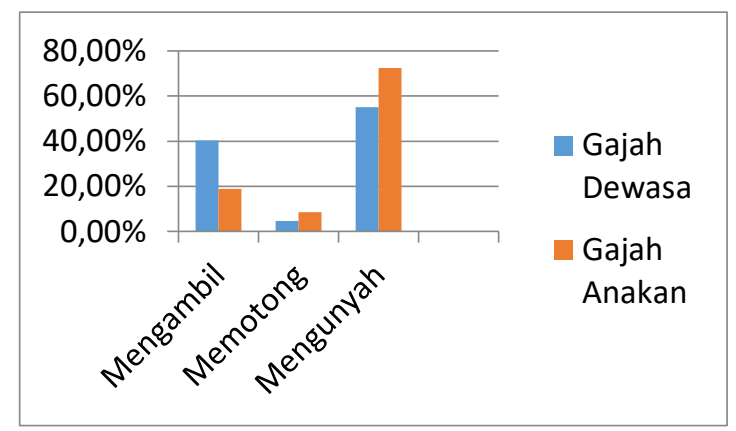

Gambar 2. Presentase frekuensi perilaku makan pada konsumsi rumput.

Lestari dan Pangeran lebih memilih untuk memakan rumput yang lebih kehijauan daripada rumput yang sudah terlihat mengering dan warnanya mulai terlihat kecoklatan. Ini disebabkan rumput yang berwarna hijau lebih banyak mengandung air sehingga lebih mudah dikonsumsi oleh anak gajah [12].

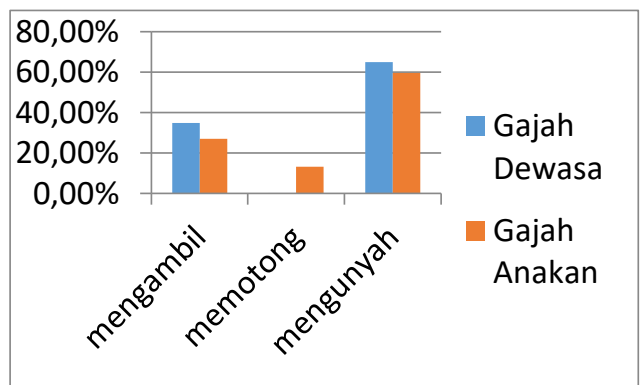

Gambar 3. Presentase frekuensi perilaku makan pada konsumsi pisang.

Agustin dan Mulyani mengkonsumsi pisang yang diberikan dengan memasukan langsung satu sisir pisang ke dalam mulutnya. Namun, pada Lestari dan Pangeran, satu sisir pisang tidak dapat dikonsumsi 
sekaligus karena ukurannya terlalu besar untuk dimasukan ke dalam mulutnya. Oleh sebab itu, mereka memerlukan cara untuk memotong satu sisir pisang sehingga dapat dimakan. Hal tersebut dapat dilihat berdasarkan Gambar 3, gajah dewasa tidak menunjukkan perilaku memotong sama sekali sedangkan pada pada gajah anakan presentasi perilaku memotongnya sebanyak $13 \%$.

Lestari dan Pangeran memakan pisangnya dengan cara menahan pisangnya dengan salah satu kaki depannya lalu satu buah pisang dililit dengan belalai dan ditarik setelah itu dimakan. Menurut [13], gajah yang masih berusia setahun tidak memiliki gigi sekuat gajah dewasa. Hal tersebut karena gigi molar gajah mulai berkembang sesuai dengan umur.

Mulyani dan Agustin memakan kelapa dengan cara memecahkannya terlebih dahulu. Lestari dan Pangeran tidak sering mengkonsumsi kelapa karena kelapa yang diberikan terbatas dan biasanya sudah diambil terlebih dahulu oleh gajah dewasa. Perilaku memotong makanan pada gajah dewasa paling besar pada makanan kelapa Hal tersebut dapat dilihat dari Gambar 4 bahwa perilaku memotong pada gajah dewasa presentasenya paling tinggi dibandingkan presentase pada Gambar 2 dan Gambar 3.

Tujuan diberikannya kelapa oleh perawat gajah Sumatera di TMR adalah untuk lebih memperbanyak produksi air susu oleh induk gajah. Menurut [14], apabila makanan sulit untuk ditangani dengan belalai untuk menjadi bagian yang diinginkan, gajah akan menendang makanannya sehingga lebih mudah untuk dimakan.

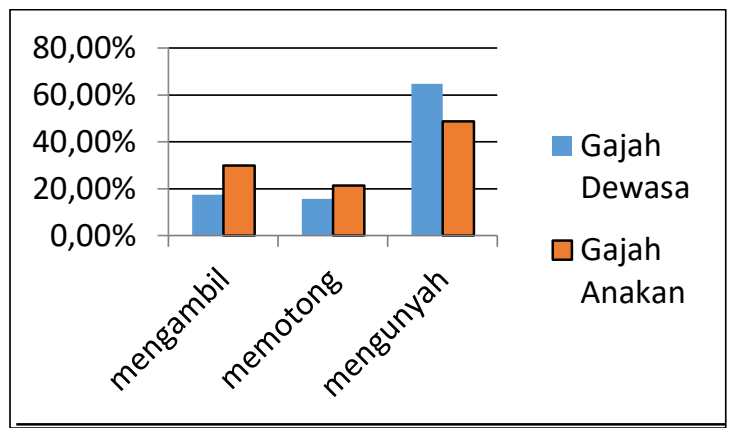

Gambar 4. Presentase frekuensi perilaku makan pada konsumsi kelapa.

Pangeran dan Lestari tidak dapat mengkonsumsi kelapa, pisang, ubi, papaya, dan jagung tanpa bantuan perawat saat usianya 3-4 bulan. Perawat gajah biasanya membantu memotong makanan seperti ubi dan pepaya menjadi bagian-bagian yang kecil sebelum diberikan kepada dua gajah tersebut. Menurut [15], anak gajah perlu mempelajari cara untuk menggunakan belalainya. Belalai gajah yang masih mudah belum dapat berfungsi seperti belalai pada gajah dewasa. Belalai tidak kaku secara fisik sehingga gajah dapat selalu memperlajari hal-hal baru dengan belalainya [13].

\section{Interaksi Gajah Sumatera Saat Aktivitas Makan}

Terdapat dua interaksi yang terjadi pada saat aktivitas makan yaitu komensalisme dan kompetisi. Interaksi komensalisme adalah interaksi yang memberi keuntungan pada satu individu namun individu lain tidak memperoleh keuntungan maupun kerugian akibat interaksi yang terjadi. Interaksi komensalisme yang terjadi yaitu saat perawat gajah mendekati kandang untuk memberi makan kepada gajah. Gajah langsung berlari ke arah perawat gajah untuk mendapatkan makanannya.

Interaksi kompetisi yaitu terjadi interaksi yang melibatkan tenaga antara kedua individu dan mengakibatkan satu individu mendapatkan kerugian. Interaksi kompetisi terjadi saat gajah sedang melakukan aktivitas makan dan ada individu lain yang berusaha mendekat, gajah akan memalingkan badannya dari arah gajah yang akan datang sambil membawa makanannya ke arahnya memalingkan badan. Cara lain untuk menghindari makanan agar tidak diambil individu lain yaitu dengan memegang makanan menggunakan belalai. Hal tersebut dapat dilihat dari cara Mulyani memegang buah kelapa yang lain dengan menggunakan belalainya pada saat ia sedang mengkonsumsi buah kelapa ketika Lestari sedang berdiri didekatnya

Hal tersebut dapat dilihat dari cara Mulyani memegang buah kelapa yang lain dengan menggunakan belalainya pada saat ia sedang mengkonsumsi buah kelapa ketika Lestari sedang berdiri didekatnya. Mulyani meletakkan kembali kelapanya di lantai ketika Lestari telah berjalan menjauhinya. Apabila gajah berhasil mencuri makanan dari individu lain, maka ia akan berjalan sekitar 1-3 meter menjauh. Gajah yang biasanya mencuri makanan adalah anak gajah. Anak gajah mencuri karena untuk memenuhi kebutuhan makan [16].

\section{KESIMPULAN}

Gajah Sumatera di TMR memiliki tiga perilaku makan yaitu mengambil makanan dan memotong makanan. Terdapat tiga teknik memotong makanan yaitu ditarik dengan menggunakan belalai, diinjak 
dengan menggunakan kaki dan ditendang dengan menggunakan kuku kaki. Anak gajah memiliki perilaku makan yang berbeda dengan gajah dewasa. Hal tersebut disebabkan oleh keterbatasan usia dan kemampuannya. Perbedaan jenis makanan berpengaruh terhadap perilaku makan gajah Sumatera di TMR

\section{DAFTAR PUSTAKA}

[1] J. F. Eisenberg and J. Shoshani, "Elephas maximus," MAMMALIAN SPECIES by The American Society of Mammalogist, no. 182, pp. 1-8, 1982.

[2] A. Gopala, O. Hadian, Sunarto, A. Sitompul, A. Williams, P. Leimgruber, P. Chambliss and S. E. d. Gunaryadi, "Elephas maximus ssp. sumatranus, Sumatra Elephant," 2013. [Online].Available: http://dx.doi.org/10.2305/IUCN.UK.20112.RLTS.T199856A9129626.en. [Diakses pada 05 Desember 2014].

[3] M. S. Walter, Management Guidelines for the Welfare of Zoo Animals: Elephants 2nd Edition., London: British \& Irish Assosiation of Zoos \& Aquariums, 2006.

[4] K. Uzunova, C. Miteva, Y. Mitev and B. Bivolarski, "Adaption and behavior of animals-indicators of their walfare," Trakia Journal of Sciences, vol. 5, no. 2, pp. 16-18, 2007.

[5] B. Schulte, "Behavior and Social Life," in Biology, Medcine, and Surgery of Elephants, lowa, Blackell Publishing, 2006, pp. 35-42.

[6] G. McKay, Behaviour and Ecology of the Asiatic Elephant in Southeastern Ceylon, Washington : Smithsonian Institution Press, 1973.

[7] Y. Biru and B. Afework, "Food habits of African elephant (Loxodonta africana) in Babile Elephant Sanctuary, Ethiopia," Tropical Ecology, vol. 53, no. 1, pp. 43-52, 2012.
[8] R. Harris, "How Do Elephants Use Adaptations For Getting Their Food," animal.mom.me, 2014. [Online]. Available: http://animals.mom.me/elephants-useadaptations-getting-food-7047.html. [Diakses pada 20 April 2016].

[9] J. Altmann, "Observational Study of Behavior: Sampling Methods," JSTOR, vol. 49, no. 3, pp. 227-267, 1974.

[10] P. A. Hidden, "Thermoregulation in African Elephants (Loxondata africana) \{disertasi\}," Faculty of Science, University of Witwatersrand, Johannesburg, 2009.

[11] R. Joshi, "Asian elephant's Elephas maximus behavior in Rajaji National Park, North-West India: eight years with Asian Elephant," Nature and Science, vol. 7, no. 1, pp. 49-77, 2009.

[12] The Garden Counselor, "Why Grass Stays Brown," The Garden Counselor, 2015. [Online]. Available: http://www.gardencounselor-lawn-care.com/why-grass-staysbrown.html. [Diakses pada 21 Mei 2015].

[13] C. Holdrege, The Flexible Giant: Seeing the Elephant Whole, New York: The Nature Institute, 2003.

[14] F. Kurt, "Physical and social development in captive born and orphaned asian elephants of the pinnewala elephant orphanage (Sri Lanka): the Captive Asian Elephant," in The International Workshop of Captive Elephant Management, India, 2002.

[15] C. Moss and C. Martyn, Elephant Memories, New York: William Morrow and Company, Inc, 1992.

[16] J. M. Chase, P. A. Abrams, J. P. Grover, S. Diehl, P. Chesson, R. D. Holt, S. A. Richards, R. M. Nisbet and T. J. Case, "The interaction between predation and competition: a review and synthesis," Ecology Letters, vol. 5, no. 2, 2002. 